\title{
PARA ALÉM DO IDEALISMO E DO MATERIALISMO: O CONCEITO HEGELIANO DE DIALÉTICA E A CRÍTICA DE MARX ÀS 'MISTIFICAÇÕES' HEGELIANAS
}

Andreas Arndt ${ }^{1}$

\section{Resumo:}

A contribuição lança um olhar crítico sobre a crítica de Marx à concepção hegeliana de dialética. A interrogação fundamental do artigo é se Marx logrou desenvolver um conceito alternativo de dialética materialista frente à dialética idealista de Hegel. Uma ampla tradição dos estudos marxistas defendeu a possibilidade de extrair d'O Capital uma dialética materialista. O problema de fundo é a discussão do status da lógica frente à filosofia real. O artigo rejeita essa possibilidade na medida em que discute criticamente o status da lógica frente à filosofia real, chegando com isso ao resultado que a aplicação de figuras da dialética hegeliana está situada no contexto da filosofia real e não serve para a fundamentação de uma dialética materialista alternativa que corresponda ao status da lógica hegeliana. $\mathrm{O}$ uso de figuras da dialética hegeliana por Marx não vai além do próprio uso que Hegel faz dessas figuras no desenvolvimento de sua própria filosofia real.

Palavras-chave: Hegel. Marx. Dialética. Idealismo. Materialismo.

\section{BEYOND IDEALISM AND MATERIALISM: HEGEL'S CONCEPT OF DIALETIC AND MARX'S CRITIQUE OF HEGEL'S 'MYSTIFICATIONS'}

\begin{abstract}
:
The contribution takes a critical look at Marx's critique of Hegel's concept of dialectic. The fundamental question of the article is if Marx succeeded in developing an alternative concept of materialist dialectic compared to Hegel's idealist dialectic. A broad tradition of Marxist studies defended the possibility of extracting a materialistic dialectic from The Capital. The fundamental problem is the discussion of the status of logic compared to real philosophy. The article rejects this possibility insofar as it critically discusses the status of logic compared to the real philosophy, thereby reaching the result that the application of figures from the Hegelian dialectic is situated in the context of the real philosophy and does not serve to substantiate a materialist dialectic alternative that corresponds to the status of Hegelian logic. Marx's use of figures in Hegelian dialectics does not go beyond Hegel's own use of these figures in the development of his own real philosophy.
\end{abstract}

Key-words: Hegel. Marx. Dialectic. Materialism. Idealism.

Alguns dias após a morte de Marx (14 de março de 1883), no dia 2 de abril de 1883, Friedrich Engels escreveu para Pyotr Lavrov, o narodnik russo, que ele iria dar uma olhada nos manuscritos de Marx para procurar e encontrar o esboço de uma dialética que Marx teria planejado escrever muito tempo atrás. ${ }^{2}$ Esse manuscrito jamais foi encontrado e provavelmente jamais tenha existido. Mas a procura por um equivalente desse esboço não cessou até hoje. Isso parece como se um grande tesouro, o Santo Graal, pudesse ser encontrado: um conceito alternativo de dialética, precisamente

1 Andreas Arndt é professor aposentado da Humboldt-Universität zu Berlin e presidente de honra da Sociedade Internacional Hegel. Traduzido do inglês por Márcio Egídio Schäfer, Doutor em Filosofia pela Humboldt-Universität zu Berlin e professor na UFMA. Contato: andreas.arndt.1@ @u-berlin.de.

2 Cf. Karl Marx and Friedrich Engels, Collected Works, London: Lawrence and Wishart 2010, vol. 47, 3 . 
oposto ao conceito hegeliano, um conceito materialista de dialética, não idealista, mas científico, revolucionário, sem nenhum misticismo. Embora nem todos os teóricos do movimento socialista internacional estivessem interessados em dialética - por exemplo, os revisionistas e os marxistas austríacos -, muitos marxistas foram cegados pelo projeto de encontrar esse tesouro. Se não havia nenhum manuscrito a ser encontrado no espólio de Marx, todo marxista interessado em dialética deve escrever a sua própria estudando as aplicações de Marx do método dialético de Hegel, especialmente na sua obra principal, O Capital. Nas palavras de Lenin, no seu Conspecto sobre a Ciência da Lógica de Hegel de 1914: "Se Marx não legou uma 'Lógica' (com letra maiúscula), ele deixou a lógica d'O Capital, e isso deve ser usado sem restrições para essa questão. N'o Capital, Marx aplicou a lógica, a dialética e a teoria do conhecimento do materialismo [três palavras não são necessárias: é uma e a mesma coisa] a uma ciência particular, que tomou tudo que tinha algum valor em Hegel e o aprimorou". ${ }^{3}$ Essa foi a certidão de nascimento do hegelo-marxismo no século XX e, em razão da eliminação dos primeiros hegelianos soviéticos por parte de Stalin, o ponto de partida do assim chamado marxismo ocidental.

Cem anos depois nós temos muitos livros e ensaios sobre dialética materialista, mas pelo menos tantos conceitos diferentes e muitas vezes contraditórios quanto autores. Por quê? Num primeiro olhar, nós podemos ver que todos esses conceitos proclamam, por um lado, a fundamentação materialista da dialética de Marx (seja o que isso for) e, de outro lado, eles usam os conceitos hegelianos (Begriffe) no contexto da Ciência da Lógica de Hegel - certamente com reservas contra o seu suposto conceito do conceito (Begriff des Begriffs) idealista, mas, contudo, numa forma determinada dentro do arcabouço da Lógica de Hegel. Como isso pode ser possível? É a forma indiferente ao conteúdo, isto é, à alegada fundamentação idealista? Ou é a forma da dialética - nas palavras de Hegel - a forma do automovimento do conteúdo? A ambiguidade dessa posição reflete exatamente a própria ambiguidade de Marx no prefácio à segunda edição do primeiro volume d'O Capital. Aqui, Marx igualmente distingue entre fundamentação e forma do método dialético: "O meu método dialético não é apenas diferente do hegeliano, mas lhe é diretamente oposto. [...] A mistificação que a dialética sofre nas mãos de Hegel não o impediu de ser o primeiro a apresentar a sua forma geral de atuar de uma maneira compreensível e consciente. Com ele ela está

3 Lenin, Collected Works, Moscow 1976, vol. 38, 317.

\begin{tabular}{|c|c|c|c|c|}
\hline Revista Dialectus & Ano 9 & n. 18 & Outubro 2020 & p. $25-38$ \\
\hline
\end{tabular}


apoiada na cabeça. Ele precisa novamente ser posta de pé se se quiser descobrir seu caroço racional dentro do seu invólucro místico." 4

No presente texto eu quero reexaminar essa afirmação e sua comprovação. Num primeiro passo eu pergunto o que a "mistificação" da dialética pode significar e o que poderia ser um conceito alternativo de dialética "materialista" (1). Depois, no segundo passo, eu quero perguntar pelo status da ideia absoluta hegeliana como método dialético na Ciência da Lógica em relação à natureza e ao espírito e à filosofia real, isto é, à filosofia da natureza e do espírito (2). Meu objetivo é provar que Marx, desde o início de sua careira filosófica e científica até a sua morte, compreendeu mal exatamente esse status da ideia absoluta, especialmente a diferença do "pensamento puro", o arcabouço categorial da nossa relação prática e teórica com o "mundo", e o pensamento do real nas ciências particulares da natureza ou do espírito. Isso será tratado nas minhas breves observações finais (3).

1.

A acusação de Marx de que Hegel mistificou o método dialético encontra-se frequentemente em sua obra - desde a sua crítica da juventude a Hegel até as afirmações no contexto de sua tardia Crítica da Economia Politica. Mas o que "misticismo" significa nesse contexto? Uma primeira indicação é dada pelo próprio Hegel. Na adição ao $§ 82$ da Lógica da Enciclopédia, nós podemos ler o seguinte: “A verdade especulativa, isso pode também ser notado, significa o mesmo que aquilo que, em conexão especial com a experiência e doutrinas religiosas, usualmente é chamado de misticismo. O termo misticismo é usado atualmente como uma regra para designar o que é misterioso e incompreensível [...] sobre o qual nós primeiramente observamos que há um mistério no místico, contudo apenas para o entendimento que é regido pelo princípio da identidade abstrata; enquanto o místico, como sinônimo de especulativo, é a unidade concreta dessas proposições, que o entendimento apenas aceita em sua separação e oposição. [...] Assim, tudo o que é racional pode igualmente ser chamado de 'místico'. Mas isso apenas é suficiente para dizer que isso transcende o entendimento. Isso de maneira alguma implica em dizer que aquilo que é dito como tal precisa ser considerado como inacessível e incompreensível ao pensamento." 5 Em outras palavras: para Hegel, 'misticismo', nesse sentido, é idêntico à racionalidade, porque ele apenas é

Marx and Engels, Collected Works, vol. 35, 19.

5 Georg Wilhelm Friedrich Hegel, Encyclopedia Logic, Indianapolis and Cambridge 1991, 133.

\begin{tabular}{|l|l|l|l|l|}
\hline Qonista Oialoctus & Ano 9 & n. 18 & Outubro 2020 & p. 25-38 \\
\hline
\end{tabular}


um mistério para o entendimento, mais precisamente, para a lógica do entendimento com o seu princípio da não-contradição. Nessa medida, o 'místico' é idêntico à dialética.

Claro que Marx não pensou que a dialética como tal é 'mística'; numa nota no primeiro volume d'O Capital, ele descreve a "contradição hegeliana" como "a fonte de toda a dialética" e, para Marx, essas contradições dialéticas precisam ser distinguidas das "contradições absurdas", isto é, daquelas da lógica ordinária do entendimento. ${ }^{6}$ Num primeiro olhar, essa posição é a mesma de Hegel na pequena Lógica. Ao mesmo tempo, no uso de Marx de 'misticismo', o termo não é usado num sentido positivo, mas negativo: o conceito-chave em sua crítica a Hegel. Para encontrar uma resposta nós precisamos olhar os contextos nos quais Marx emprega o [termo] 'misticismo'.

Numa carta a Engels (16 de janeiro de 1858) Marx escreveu: “O que para mim foi de grande serventia no que tange à questão do método de tratamento foi a Lógica de Hegel, sobre a qual eu lancei mais um olhar por mero acidente. [...]. Se um dia chegar o tempo em que semelhante trabalho novamente for possível, eu gostaria muito de escrever duas ou três folhas para tornar acessível ao leitor comum o aspecto racional do método que Hegel não somente descobriu, mas também mistificou". ${ }^{7}$ Cerca de quatro meses depois, numa carta a Ferdinand Lassalle, Marx enfatiza o mesmo ponto crítico: "Ademais, eu gostaria de ter encontrado no próprio texto algumas indicações críticas sobre sua atitude frente à dialética hegeliana. Essa dialética é, para ter certeza, a última palavra na filosofia e, dessa maneira, tudo o que temos que fazer é despi-la de sua aura mística dada a ela por Hegel". ${ }^{8}$ Marx critica a dialética hegeliana como "mistificada" ou com uma "aura mística" por um lado e, por outro, louva essa dialética como "a última palavra na filosofia". Claro que o elogio é também ambíguo. A dialética hegeliana poderia ser entendida como a última palavra no sentido de a última palavra já falada na filosofia; ou dialética poderia ser compreendida como a última palavra que em geral poderia ser dita na filosofia. Ademais, a sentença poderia ser lida com ênfase em

6 Marx and Engels, Collected Works, vol. 35, 592 “John St. Mill, ao contrário, aceita, por um lado, a teoria ricardiana do lucro, e anexa, por outro, a 'remuneração de abstinência' de Senior. Ele está tão familiarizado com contradições absurdas quanto se sente perdido na contradição hegeliana, a fonte de toda a dialética. Jamais ocorreu ao economista vulgar de fazer a simples reflexão de que toda a ação humana pode ser vista como 'abstinência de seu oposto'. Comer é a abstinência de jejuar, caminhar é abstinência de ficar parado, trabalhar é abstinência de vagabundear, vagabundear é abstinência de trabalhar etc. Esses senhores fariam bem em ponderar ao menos uma vez sobre Espinoza: 'Determinatio est Negatio"'.

7 Marx e Engels, Collected Works, vol. 40, 249.

8 Marx a Lassalle, 31.05.1858, in: Ibid., 316.

\begin{tabular}{|l|c|c|c|c|}
\hline Q Rovista Oialectus & Ano 9 & n. 18 & Outubro 2020 & p. 25-38 \\
\hline
\end{tabular}


"filosofia": a dialética de Hegel poderia ser a última palavra da filosofia, porque a filosofia em geral chegou a um fim e precisa ser substituída pelas ciências empíricas. De fato, essa era a visão de Marx na Ideologia Alemã, na qual nós podemos ler a seguinte sentença: “A observação empírica precisa, em cada caso, trazer à tona empiricamente, e sem nenhuma mistificação e especulação, a conexão entre a estrutura social e política com a produção". ${ }^{9}$ Marx jamais revogou essa posição e a substituição da filosofia pelas ciências empíricas é, por fim, aquilo que a assim chamada fundamentação materialista da dialética significa.

Dessa maneira, eu gostaria de sugerir a seguinte leitura: a dialética hegeliana é a última palavra da filosofia de um ponto de vista filosófico, mas a dialética precisa ser fundada de novo nas ciências empíricas, após o fim da filosofia. Assim, numa primeira aproximação, nós podemos dizer que, para Marx, a filosofia em geral e, nessa medida, o conceito filosófico de racionalidade, parece ser um certo tipo de misticismo. Por quê? O problema de Marx é a decisão hegeliana pelo "pensamento puro" como ponto de partida da Ciência da Lógica: "a ciência deveria ser precedida por uma dúvida universal, isto é, por uma total ausência de pressuposição. Falando de modo estrito, esse requisito é preenchido pela liberdade que abstrai de tudo, e compreende a sua pura abstração, a simplicidade do pensar-em a decisão da vontade de pensar puramente." 10 Na visão de Marx, a ausência de pressuposição é uma pressuposição ideológica. No manuscrito da Ideologia Alemã, Marx enfatizou que a separação do pensamento das condições empíricas dará "uma conexão mística entre [...] as ideias, a qual será tratada considerando-as como 'formas da autodeterminação do conceito' (isso é possível porque, em virtude de sua base empírica, essas ideias realmente estão conectadas umas às outras e porque, concebidas como meras ideias, elas recebem autodistinções, distinções feitas pelo pensamento)". ${ }^{11}$ A propósito, isso não é um argumento original, mas uma crítica corrente nas discussões sobre a Lógica de Hegel no século XIX e ele foi usado por Friedrich Adolf Tredelenburg em suas Investigações Lógicas, em que ele afirma que o desenvolvimento lógico dos conceitos e das categorias na Ciência da Lógica não é um tipo de automovimento, mas dependente do movimento na realidade. Mais tarde, nos Grundrisse, Marx usará o mesmo argumento numa autocrítica à "maneira idealista de apresentação, a qual gera a

Karl Marx e Friedrich Engels, The German Ideology, part one, ed. By C.J. Arthur, New York 2004, 46.

10 Hegel, Encyclopedia Logic, Indianapolis and Cambridge, 1991, 124.

11 Marx and Engels, Collected Works, vol. 5, 62.

\begin{tabular}{|l|l|l|l|l|}
\hline Rovista Dialectus & Ano 9 & n. 18 & Outubro 2020 & p. 25-38 \\
\hline
\end{tabular}


aparência como se isso fosse meramente uma questão de definição de conceitos e da dialética desses conceitos." 12 Para Marx, essa "maneira idealista" é exatamente a maneira hegeliana de pensar: "O concreto é concreto, porque ele é a síntese de muitas determinações, desse modo, a unidade do diverso. Por essa razão, no pensamento, isso aparece como um processo de síntese, como um resultado, não como ponto de partida da percepção e conceituação. [...] Hegel, por isso, caiu na ilusão de compreender o real como resultado do pensamento que se sintetiza em si, se aprofunda em si e se move por si; de fato, o método de avançar do abstrato ao concreto é simplesmente a via pela qual o pensamento assimila o concreto e o reproduz como um concreto mental. Mas, de modo nenhum, o processo de gênese do próprio concreto". ${ }^{13}$

Agora nós podemos entender os primeiros passos do processo de mistificação tal como ele aparece aos olhos de Marx. Primeiro passo: o concreto como o real, como uma totalidade (por exemplo, uma dada sociedade) precisa ser transferido para uma sequência de determinações conceituais e, por essa via, ser reproduzido como um "concreto no pensamento" (Gedankenkonkretum). Esse passo não é um ato de mistificação, mas necessário para todo o pensamento científico. Nessa medida, Marx marcha com Hegel e critica implicitamente a ingenuidade de seu empirismo na Ideologia Alemã. Apenas o segundo passo faz a diferença. Na filosofia de Hegel, para Marx, o processo de reproduzir o concreto real como um concreto no pensamento independentizou-se frente ao real. Este é o bem conhecido argumento de que o autodesenvolvimento do pensamento substitui os processos na realidade. Enquanto o pensamento agora parece ser o fundamento de si mesmo, o sujeito - subiectum ou hypokeimenon - se transformou: o ideal toma o lugar do real. Mas essa substituição é apenas o primeiro; finalmente, num terceiro passo, o sujeito no sentido de hypokeimenon torna-se o sujeito no sentido de uma subjetividade pessoal, autorrelacionada: o método dialético hegeliano como ideia absoluta. Esse passo final é, por um lado, a consequência do anterior, mas, por outro, a transformação do hypokeimenon numa pessoa autorrelacionada é algo similar a um superadditum. Na Ideologia Alemã, Marx escreveu - aqui contra os seus os seus ex-companheiros jovens hegelianos, a saber, Bruno Bauer e Max Stirner -: "Para remover a aparência mística deste 'conceito autodeterminante', ele é transformado numa pessoa - 'consciência-se-si' - ou, para aparecer completamente materialista, numa série de pessoas [...]. Assim, o

12 Marx and Engels, Collected Works, vol 28, 89.

13 Ibid., 38.

\begin{tabular}{|c|c|c|c|c|}
\hline Gevita Dialectus & Ano 9 & n. 18 & Outubro 2020 & p. $25-38$ \\
\hline
\end{tabular}


corpo inteiro de elementos materialistas foi removido da história e se pode, agora, soltar completamente as rédeas do corcel especulativo." ${ }^{14}$ Quase o mesmo argumento é usado por Marx em sua famosa afirmação no posfácio à segunda edição do primeiro volume de $O$ Capital: "Evidentemente, o método de apresentação precisa ser formalmente diferente daquele da pesquisa. $\mathrm{O}$ último precisa apropriar o material em detalhe, analisar as diferentes formas de seu desenvolvimento, estabelecer as suas conexões internas. [...] Quando isso tiver sido feito de maneira exitosa, então isso pode nos parecer como se tivéssemos diante de nós uma construção meramente a priori. Meu método dialético não é apenas diferente do hegeliano, mas lhe é diretamente oposto. Para Hegel, o processo vital do cérebro humano, isto é, o processo do pensar, o qual, sob o nome de 'ideia', ele inclusive transforma num sujeito independente, é o demiurgo do mundo real, e o mundo real é apenas a forma externa, fenomenal da 'ideia'. Para mim, ao contrário, o ideal não é nada mais do que o mundo material refletido pelo pensamento humano e traduzido na forma de pensamentos". ${ }^{15}$

$\mathrm{Na}$ compreensão de Marx, a substituição do hypokeimenon e sua transformação num sujeito autorrelacionado, a ideia absoluta, isto é, o método dialético, constitui a mistificação da dialética de Hegel. É como o "caráter místico das mercadorias", que, segundo Marx, baseia-se num "quid pro quo", numa confusão entre valor de uso e valor de troca. ${ }^{16}$ Quid pro quo é uma fórmula geral para aquilo que Marx entende por misticismo. No que concerne à dialética de Hegel, Marx considera que a permuta do hypokeimenon real pela 'ideia' é a inversão fundamental. O modelo para essa crítica procede originalmente de Feuerbach e de sua crítica à religião na sua Essência do Cristianismo. Para Feuerbach, o sujeito real - o ser humano - foi substituído por um sujeito imaginário, Deus. Aos olhos de Marx, o Deus de Feuerbach é a ideia absoluta, "o demiurgo do mundo real", como ele escreveu em O Capital. Falando estritamente, a crítica de Marx a Hegel, também em $O$ Capital, é um resquício do período anterior à sua ruptura com o movimento dos jovens hegelianos na Ideologia Alemã de 1845. Essa também foi uma ruptura com a filosofia em geral a favor das ciências empíricas; contudo, na sua Crítica da Economia Política, Marx não foi um empirista, não obstante suas referências a Hegel: desse período em diante Marx não refletiu sobre as pressuposições filosóficas ou sobre as consequências filosóficas das

14 Marx and Engels, Collected Works, vol. 5, 62.

15 Marx and Engels, Collected Works, vol. 35, 19.

16 Ibid., 82s e 6.

\begin{tabular}{|l|l|l|l|l|}
\hline Rovista Dialeatus & Ano 9 & n. 18 & Outubro 2020 & p. 25-38 \\
\hline
\end{tabular}


ciências particulares. Desde 1845 ele pensou ter concluído com a matéria filosófica, mas, de fato, ele não estava [pronto] e a ausência de reflexão filosófica é o ponto cego da pesquisa científica de Marx: ele sempre teve que retornar à última palavra da filosofia para levar a termo a Crítica da Economia Política, não obstante o alegado caráter místico da dialética hegeliana.

O uso de Marx do método dialético de Hegel é ele mesmo um mistério, porque esse método é idêntico com a ideia absoluta na Ciência da Lógica. Para Hegel, Deus - a noção filosófica de Deus - é o método dialético. Marx teve pleno conhecimento disso quando escreveu que a ideia de Hegel é "o demiurgo do mundo real". O demiurgo não é o criador, mas, tal como Deus no Timeu de Platão, mais como um artista, remodelando a matéria dada do mundo dado. Aos olhos de Marx, aqui o quid pro quo se torna crucial: a remodelação do real, isto é, sua transformação em conceitos e sua reprodução no pensamento não segue a lógica da matéria empírica particular, mas a lógica do autodesenvolvimento das categorias no pensamento. Em sua Crítica à Filosofia do Direito de Hegel de 1843, Marx escreveu: "Não a filosofia do direito, mas a lógica é o centro real de interesse. O trabalho filosófico não consiste em encarnar o pensamento em definições políticas, mas na evaporação das definições políticas existentes em pensamentos abstratos. Não a lógica da coisa, mas a coisa da lógica é o elemento filosófico. A lógica não serve para provar o Estado, mas o Estado para provar a lógica". ${ }^{17}$ Desde então, Marx repetiu esse argumento várias vezes, em muitas variações, mas o argumento por essa via não melhorou. O cerne de sua admissão é que, para Hegel, a sequência e a inter-relação dos conceitos e das categorias dentro do "pensamento puro" são semelhantes como na realidade, isto é, nas filosofias da natureza e do espírito. Para provar essa admissão, seria necessário poder extrair a estrutura da Ciência da Lógica, por exemplo, da Filosofia do Direito de Hegel; isso é tão impossível quanto extrair uma concepção alternativa de dialética d'O Capital de Marx. Para Hegel, a "lógica específica do sujeito específico", ${ }^{18}$ a qual Marx exige, é a consequência do status da ideia absoluta na sua relação com a natureza e o espírito.

2.

O método dialético é a ideia absoluta, isto é, a dialética é, em primeira linha, o método do puro pensar. O pensamento puro é o pensamento que se pensa a si mesmo,

17 Marx and Engels, Collected Works, vol. 3, 18.

18 Ibid., 91.

\begin{tabular}{|l|l|l|l|l|}
\hline Qonista Dialoctus & Ano 9 & n. 18 & Outubro 2020 & p. 25-38 \\
\hline
\end{tabular}


baseado na nossa decisão voluntária de querer pensar puramente, isto é - nas palavras de Hegel - "deixando de lado toda reflexão, tomando simplesmente aquilo que está aí, diante de nós". ${ }^{19}$ Dessa maneira, a Ciência da Lógica inicia com o ser puro como "o imediato indeterminado", ${ }^{20}$ o pensamento sem nenhum conteúdo particular, exceto o pensamento enquanto tal: “Tampouco há algo a ser pensado nele, ou ele é, igualmente, apenas esse pensamento vazio. O ser, o imediato indeterminado, é de fato o nada, e nem mais nem menos do que o nada." 21 Refletindo sobre isso, nós podemos ver que a indeterminidade do ser é "apenas em oposição àquilo que é determinado ou

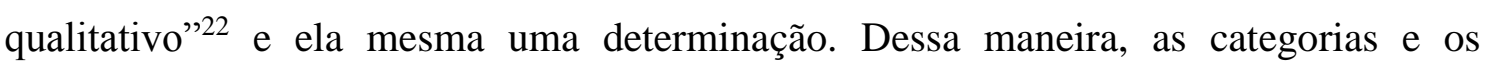
conceitos do pensamento podem ser desenvolvidos dentro do pensamento puro. Por fim, podemos entender que as categorias e os conceitos como meios do nosso pensamento ou refletindo o pensamento são semelhantes às categorias e aos conceitos do pensamento; assim, o conceito está compreendendo a si mesmo e isso é o ponto de vista da ideia absoluta. Deste ponto de vista, todo o desenvolvimento através de todas as três partes da Ciência da Lógica - Ser, Essência e Conceito - pode ser reconstruído post festum como automovimento do conceito; esse é o método dialético enquanto ideia absoluta. Isso não é uma simples repetição do movimento lógico, mas uma nova perspectiva sobre ele através do conhecimento de que os conceitos do nosso pensamento do pensar - o pensamento puro - não são diferentes do conceito que nós pensamos e, desse modo, que os conceitos são absolutamente autorrelacionados. Esse método é, de acordo com Hegel, a forma do automovimento do seu conteúdo, mas o conteúdo não é nada mais do que a forma lógica, de modo que o método é a autorrelação da forma. Porque a ideia é tanto teórica como praticamente, o método dialético de Hegel não descreve a lógica de um pensamento ou ação próprio em relação a um objeto próprio, mas a estrutura geral de todo o nosso comportamento teórico e prático para com o 'mundo'. Ele é uma rede categorial que nós precisamos usar e atualizar em cada pensamento concreto.

Esse é o ponto crucial para compreender a incompreensão de Marx de Hegel. O método dialético de Hegel não reivindica ser o método de apreender um objeto particular teórica ou praticamente. Ademais, a estrutura da ideia absoluta - a absoluta autorrelacionalidade do conceito como tal - jamais poderia ser a estrutura de qualquer realidade abaixo do nível do espírito absoluto, porque as formas da natureza, do espírito

19 Georg Wilhelm Friedrich Hegel, The Science of Logic, vol. 3, 18.

20 Ibid., 59.

21 Ibid., 69.

22 Ibid., 58.

\begin{tabular}{|l|l|l|l|l|}
\hline Revista Dialectus & Ano 9 & n. 18 & Outubro 2020 & p. 25-38 \\
\hline
\end{tabular}


subjetivo e objetivo são finitas e, nessa medida, não absolutamente autorrelacionadas, mas relacionadas a uma outra. A propósito: o discurso de Marx dos "limites da dialética" no manuscrito dos Grundrisse não pode ser entendido seriamente como uma objeção geral a Hegel, porque para Hegel todo sistema real abaixo do nível do absoluto - como o sistema da sociedade civil-burguesa analisado por Marx - é limitado. Dessa maneira, inclusive Hegel teve que manter em mente a diferença do método dialético em geral e a estrutura particular de um real, e seu pensamento e ação sobre ele. Embora as categorias e os conceitos do pensamento puro sejam geralmente válidos para todo pensamento ou ação objetivo e, nessa medida, a priori para os sujeitos finitos, os portadores do pensamento e da ação, nós precisamos considerar que o método de desenvolvimento interno dessas categorias e desses conceitos dentro do pensamento puro não é o mesmo que a sequência e interrelação das categorias e dos conceitos em relação ao próprio objeto. Por essa razão, num primeiro olhar, o uso assistemático de Marx das categorias hegelianas - assistemático, porque não segue as suas sequências internas na Ciência da Lógica - não indica um conceito alternativo de dialética, isto é, a dialética 'materialista', mas a necessidade de reproduzir estruturas específicas de objetos específicos pelo pensamento. O uso de Hegel por Marx na sua Crítica da Economia Política poderia ser analisado completamente dentro das pressuposições do arcabouço da filosofia de Hegel. O próprio Hegel está fazendo o mesmo nas suas filosofias do real, isto é, as filosofias da natureza e do espírito.

Mas o que dizer sobre a alegada 'mistificação'? Para entender por que a ideia absoluta de Hegel não é um quid pro quo no sentido das objeções de Marx, nós precisamos nos perguntar sobre o status dessa ideia. Primeiro: a ideia absoluta é um método e não uma entidade, e não poderia ser imaginada como tal. Inclusive, para Hegel, Deus não é uma entidade à parte como nas projeções humanas criticadas por Feuerbach, porque como uma tal entidade, à diferença de e ao lado de outras entidades, ele seria finito e não absoluto. Uma vez que a ideia, Hegel escreveu: "contém toda determinidade dentro de si, e sua essência consiste em retornar a si mesma através de sua autodeterminação e particularização, ela tem várias formas, e a tarefa da filosofia é reconhecê-la nestas [formas]. A natureza e o espírito são, em geral, diferentes modos de apresentar sua existência, arte e religião diferentes modos de apreender a si mesma e de dar-se a si mesma uma existência apropriada". ${ }^{23}$ Nós precisamos ler isso atentamente: a

23 Ibid., 735 .

\begin{tabular}{|l|l|l|l|l|}
\hline Rovista Cialectus & Ano 9 & n. 18 & Outubro 2020 & p. 25-38 \\
\hline
\end{tabular}


natureza e o espírito são modos de apresentação da existência da ideia (das Dasein der Idee darzustellen). Em outras palavras: fora da operação do pensamento puro - um processo que também exige sujeitos finitos enquanto portadores do pensamento - a ideia não tem nenhuma existência independente e precisa ser procurada e recobrada na natureza e no espírito. Nas palavras de Hegel: a ideia é, "por essa razão, não apenas a força superior da razão, ou mais propriamente sua única e absoluta força, mas também o único e superior impulso da razão de encontrar-se e reconhecer-se a si mesma e através de si mesma em todas as coisas. " ${ }^{24}$ Exatamente em oposição à opinião de que Hegel apenas estava interessado nas estruturas lógicas, ele confrontou-se com a necessidade de provar as categorias lógicas no reconhecimento do real. Dessa maneira, o mundo empírico da aparência [appearing] como pressuposição do conhecimento do real não se foi com ou foi substituído pela ideia, mas suprassumido no bem conhecido sentido hegeliano.

Por essa razão, Hegel descreve sua posição filosófica como [estando] para além da oposição do idealismo e do realismo (e nós podemos dizer: também do materialismo): "A afirmação de que o finito é uma idealização define o idealismo. $\mathrm{O}$ idealismo da filosofia não consiste em nada mais do que no reconhecimento de que o finito não é verdadeiramente um existente. Toda filosofia é essencialmente idealismo ou pelo menos tem o idealismo por seu princípio, e então a questão é somente em que medida esse princípio é levado a termo. [...] Por essa razão, a oposição entre filosofia idealista e filosofia realista é destituída de sentido. [...] Os princípios da filosofia antiga, bem como de filosofias mais recentes [...] são universais, idealizações, não coisas como dadas imediatamente, isto é, numa singularidade sensível." ${ }^{25}$ Hegel jamais caracteriza sua filosofia como ‘idealismo' e particularmente não como um “idealismo absoluto" em oposição ao materialismo ou ao realismo. $\mathrm{Na}$ sua Enciclopédia, ele avalia expressamente o materialismo como a contrapartida para o dualismo. ${ }^{26} \mathrm{O}$ idealismo é apenas a crítica do pensamento e da lógica do entendimento (Verstand), o qual lida com entidades finitas fixas. Dessa maneira, o idealismo no sentido hegeliano é idêntico à negatividade do método dialético: "A negação é, assim, determinada como idealidade; o idealizado é o finito como ele é no verdadeiro infinito - como uma determinação, um conteúdo, um distinto, mas não um existente subsistente, mais propriamente um

24 Ibid., 737.

25 Ibid., 124

$26 \S 389$, Adendo.

\begin{tabular}{|c|c|c|c|c|}
\hline Q Rovita Dialectus & Ano 9 & n. 18 & Outubro 2020 & p. $25-38$ \\
\hline
\end{tabular}


momento." ${ }^{27}$ Isso é o mesmo processo como na Crítica da Economia Política de Marx, quando ele critica os assim chamados economistas vulgares por pensarem em entidades finitas e pela sua lógica do entendimento. Para Hegel, a maneira como Marx trata a dialética também seria 'idealista' e Marx não teria motivo para responder, exceto sua recusa do termo 'idealista'.

Nós já aprendemos que para Marx, portanto, a ideia absoluta de Hegel não é um deus como um criador e que, portanto, essa ideia existe somente no processo do pensamento (nosso pensamento, não o pensamento de uma divindade), e que a natureza e o espírito são os modos de mostrar a existência da ideia; dessa maneira, a ideia absoluta é apenas o método do pensamento e do agir objetivos em geral. Isso sugere que o método dialético - e com ele toda a Ciência da Lógica - é o resultado de uma abstração. De fato, nós podemos dizer que o começo da Lógica com a decisão de pensar puramente é um ato de abstração - em primeira linha de tudo aquilo que nós acreditamos saber sobre o pensamento, mas também da natureza e do espírito. Isso ocorre porque a natureza do espírito é a liberdade e a abstração é um ato de liberdade ou volição. No § 382 da Enciclopédia Hegel disse que o espírito "pode se recolher a si mesmo de tudo aquilo que é externo e de sua própria exterioridade, de sua verdadeira existência [...] Tudo isso é possível pelo tempo em que ele for considerado em sua universalidade abstrata autônoma." ${ }^{28}$ Ao fim da Ciência da Lógica, no capítulo sobre a ideia absoluta, Hegel volta a essa posição, enfatizando que "essa ideia ainda é lógica; ela está encerrada no pensamento puro, a ciência apenas do conceito divino. A sua exposição sistemática é evidentemente uma realização, mas uma [realização] confinada dentro da mesma esfera. Porque a ideia do conhecimento é, nessa medida, encerrada dentro da subjetividade, ela é o impulso para suprassumi-la, e a verdade pura torna-se como resultado final também o começo de uma outra esfera e ciência."29

A subjetividade, isto é, a pura autorrelacionalidade é como um cárcere para a ideia, porque seu objetivo é o pensamento e a ação objetivos e, por essa razão, a realização na realidade da natureza e do espírito. Essa realização, o passo do pensamento puro à realidade da natureza, parece bastante misterioso. Muitos intérpretes o tomaram como uma narrativa baseada no mito bíblico da criação do mundo narrada pelo evangelista João (1, 1-3): "No início era o verbo, e o verbo estava com Deus, e o

27 Hegel, The Science of Logic, Cambridge 2010, 119.

$28 \S 282$.

29 Hegel, The Science of Logic, Cambridge 2010, 752.

\begin{tabular}{|l|c|c|c|c|}
\hline Qovista Oialectus & Ano 9 & n. 18 & Outubro 2020 & p. 25-38 \\
\hline
\end{tabular}


verbo era Deus. Ela estava no princípio com Deus. Todas as coisas foram feitas por meio dele, e sem ele, nenhuma coisa que foi feita teria sido feita". Essa interpretação não pode ser correta, porque um ato de criação obviamente seria um ato de transição, mas Hegel enfatiza que o passo para a natureza "não é nada que tenha se tornado, não é uma transição [...] A transição há de ser compreendida, por isso, no sentido de que a ideia se entrega livremente ela mesma, absolutamente certa de si e internamente em repouso. Por conta dessa liberdade, a forma de sua determinidade é como que absolutamente livre: a externalidade do espaço e do tempo existente absolutamente para si mesma sem subjetividade." 30

Eu quero salientar dois pontos cruciais dessa citação. Primeiro: que a ideia se entrega livremente ela mesma poderia ser compreendido como uma fuga do cárcere: a ideia está deixando o cárcere do pensamento puro, da lógica, numa palavra: da abstração. Assim como a abstração é um ato da volição, assim também o retorno da abstração é um ato da volição, da descarga livre. Sob essa ótica, o passo da ideia absoluta para a realidade da natureza não é, em nenhum aspecto, místico. O segundo ponto: a natureza - a externalidade do espaço e do tempo - é "existente absolutamente para si mesma”. 'Absolutamente' significa: a existência da natureza não é dependente de algo outro, por exemplo, da ideia. Por essa razão, a natureza estava lá desde o início e a Lógica foi apenas abstraída da natureza. Dessa maneira, não obstante a Lógica seja a primeira parte do sistema, seguida pela natureza e pelo espírito, de acordo com os três silogismos da filosofia de Hegel no fim da Enciclopédia, nós também podemos começar com a natureza como a pressuposição do espírito. A alegada objeção de Marx contra Hegel, de que é necessário ter um sujeito real (hypokeimenon) antes do pensamento, é também simplesmente integrada à posição de Hegel.

3.

Permitam-me resumir brevemente. Eu não consegui achar nenhum misticismo em Hegel em nenhum lugar. A crítica de Marx é baseada numa incompreensão que procede do discurso dos jovens hegelianos, do qual Marx participou do início até a metade dos anos de 1840. Na sua ruptura entre ele e seus companheiros jovens hegelianos anteriores, Marx passou programaticamente da filosofia para as

30 Ibid, 753.

\begin{tabular}{|l|l|l|l|l|}
\hline Rovista 2 ialectus & Ano 9 & n. 18 & Outubro 2020 & p. 25-38 \\
\hline
\end{tabular}


ciências empíricas, mas quando ele voltou a Hegel no desenvolvimento de sua Crítica da Economia Política, Marx não pensou acerca da necessidade de uma nova reflexão filosófica acerca de sua utilização do método dialético. Pode-se assumir que o manuscrito dolorosamente perdido sobre o método dialético hegeliano daria somente alguns exemplos das figuras do pensamento de Hegel no contexto de sua Crítica da Economia Política, mas não uma fundamentação inteiramente nova da dialética, em todo caso não uma fundamentação convincente. A admissão de Marx de um quid pro $q u o$ - a substituição de um hypokeimenon real por um sujeito imaginário, a ideia, é uma incompreensão completa do status da Ciência da Lógica em geral e da ideia absoluta em particular. Desde a sua Crítica da Filosofia do Direito de Hegel de 1843 até as suas últimas referências a Hegel, Marx teve a tendência de misturar a Lógica e a Filosofia real, conectando imediatamente o pensamento puro e o pensamento objetivo. Mas novamente: o uso produtivo de Marx do método dialético hegeliano pode, de fato, ser descrito e compreendido inteiramente no solo da filosofia de Hegel - uma filosofia sem misticismo.

\begin{tabular}{|c|c|c|c|c|}
\hline Rovista Dialectus & Ano 9 & n. 18 & Outubro 2020 & p. $25-38$ \\
\hline
\end{tabular}

